\title{
INCLUSÃO DE UMA ALUNA CEGA EM UM CURSO DE LICENCIATURA EM QUÍMICA
}

\section{Inclusion of a blind student in a chemistry education teachers' undergraduate program}

\author{
Anelise Maria Regiani ${ }^{1}$ • Gerson de Souza Mól ${ }^{2}$
}

Resumo: A partir do ingresso de uma aluna cega no curso de licenciatura em Química de uma universidade pública, foi desenvolvida a presente reflexão sobre a inclusão de alunos deficientes visuais em cursos superiores de Química. Os docentes deste curso responderam a um questionário no qual expressaram temores e ideias sobre inclusão e iniciativas em sala de aula. Verificou-se que a educação inclusiva neste nível requer a reconstrução do sistema de ensino, com superação de várias barreiras pedagógicas. A maioria dos docentes apontou a carência de materiais didáticos e o despreparo para a interação com as necessidades específicas como causa principal da dificuldade na formação da discente cega. Apesar disso, a presença e a convivência desta aluna com os colegas contribuem para a formação de professores mais capacitados para lidar com as diferença, por vivenciarem o processo de inclusão e, dessa forma, acreditarem que isso é possível e viável.

Palavras-chave: Deficiente visual. Necessidade educacional especial. Ensino Superior. Ensino de Química. Inclusão.

\begin{abstract}
From the entrance of a blind student in chemistry course at a public university in Brazil this reflection was developed about the inclusion of the visually impaired in college chemistry. The teachers of this course answered a questionnaire where they expressed their fears and ideas on inclusion and initiatives in the classroom. It was found that inclusive education at this level requires the reconstruction of the educational system to overcome pedagogical barriers. Most teachers pointed to the lack of instructional materials and their own unpreparedness as causes of failure in teaching for this student. On the other hand, her presence and interaction with colleagues contributed to the formation of more qualified teachers able to handle the difference. Experiencing a process of inclusion make them believe that this is possible and feasible.
\end{abstract}

Keywords: Visually impaired. Special educational need. College teaching. Chemistry teaching. Inclusion.

\footnotetext{
${ }^{1}$ Centro de Ciências Biológicas e da Natureza (CCBN), Universidade Federal do Acre (UFAC). BR 364, Km 04, Distrito Industrial. Rio Branco, AC, Brasil. 69.915-900. anelise_regiani@yahoo.com.br

${ }^{2}$ Instituto de Química, Universidade de Brasília (UnB). Brasília, DF, Brasil.
} 
Regiani, A. M.; Mól, G. S.

\section{Introdução}

No Brasil, o acesso à educação de pessoas com necessidades especiais passou a ser oferecido de forma mais efetiva a partir da década de 1990, com a promulgação da lei 9.394/ 96, que estabelece as Diretrizes e Bases da Educação Nacional (BRASIL, 1996). Esta define, no seu artigo número 58, a Educação Especial como modalidade de educação escolar oferecida a educandos portadores de necessidades especiais, e preconiza o seu oferecimento, em preferência, na rede regular de ensino (BRASIL, 1996). Desde então, a reflexão sobre as políticas educacionais tem provocado a mudança do comportamento segregacionista para a flexibilidade e adaptação do sistema educativo. Pacheco e Costas (2006) afirmam que os princípios atualmente sustentadores da Educação Especial estão fundamentados nos direitos à educação, à igualdade de oportunidades e à participação na sociedade. Em decorrência dos avanços verificados nos diferentes graus de ensino, surge um novo desafio: a inclusão de alunos com necessidades educacionais especiais na educação superior.

Apesar de a legislação brasileira de Ensino Superior dispor sobre os requisitos de acessibilidade de pessoas deficientes para instruir os processos de autorização e reconhecimento de cursos e de credenciamento de instituições (portaria 3.284/2003), não existem dados oficiais (MOREIRA, 2005) sobre a educação superior, e a maioria das universidades não dispõe de mapeamento sobre o ingresso e a permanência desses alunos. Ferreira (2007) descreve iniciativas pontuais de algumas universidades no atendimento às Necessidades Educacionais Especiais (NEE) de seus discentes. Thoma (2006) revela instituições e corpos docentes despreparados para a efetiva inclusão educacional.

Segundo Ferreira (2007), para efetivar a inclusão, as NEE do indivíduo devem ser atendidas em toda a sua trajetória escolar - acesso, ingresso, permanência e saída. Ferreira (2007) indica que a permanência desse indivíduo na universidade implica um trabalho constante, em frequência, participação, dedicação e vigilância cotidiana das obrigações acadêmicas. Assim, concordando com Rodrigues (2004), consideramos que, para a universidade assegurar o direito à educação e à igualdade de oportunidades, é obrigatória a reflexão, não somente sobre as condições de acesso, mas, também, sobre as condições de sucesso que ela é capaz de proporcionar a seus alunos. É primordial saber responder a questões sobre o significado da qualidade no processo ensino-aprendizagem. O apoio institucional necessário não se dá somente na disponibilização da infraestrutura e uns poucos profissionais especialistas ou interessados em educação especial. Os principais obstáculos à educação inclusiva em nível superior, reportados por Rocha e Miranda (2009), são as condições didático-pedagógicas de trabalho de professores e a falta de condições adequadas de ajuda para operacionalização de processos de aprendizagem e inclusão plenas destes alunos. O ensino inclusivo, sobretudo em nível superior, não deve ter caráter filantrópico e assistencialista. É função da universidade mostrar com clareza as contradições sociais e propor alternativas concretas, pois é nesse contexto que está a perspectiva de incluir (MOREIRA, 2005), ou seja, a universidade não pode ser entendida apenas como uma instalação física ou um conjunto arquitetônico, mas deve ser pensada como uma organização social, responsável por um ensino de qualidade.

Sobre o despreparo dos docentes para o ensino em nível superior, Rodrigues (2004) afirma que a universidade pouco reflete sobre a pedagogia, as metodologias e as causas de sucesso e de insucesso de seus alunos. Também aponta que as principais dificuldades no En- 
sino Superior, seja ele inclusivo ou não, são decorrentes de o processo ensino-aprendizagem ser considerado como uma transferência de informação e de a universidade atribuir exclusivamente ao estudante a responsabilidade da aprendizagem. A universidade ainda não alterou os paradigmas do professor detentor do conhecimento, da hipotética vocação pedagógica e do aluno receptor e único responsável pela busca de conhecimento. Os docentes universitários nem sempre estão preparados para atuarem como mediadores do conhecimento e, raramente, assumem posturas reflexivas em suas atuações didáticas. O reflexo deste despreparo docente é ainda maior na perspectiva do ensino inclusivo. Pacheco e Costas (2006) apontam a formação docente como um dos maiores obstáculos para a inclusão, relatando que muitos professores só adquirem informação e formação sobre alunos com necessidades educacionais especiais quando se encontram com eles na sala de aula. Os sentimentos de ansiedade e rejeição do docente para com estes discentes surgem do pouco ou nenhum conhecimento sobre estes alunos em sua formação inicial. Este fato se agrava porque grande parte dos docentes das áreas duras das ciências é bacharel, e não licenciado.

Concordamos com Castanho e Freitas (2005) quando afirmam que, além de políticas públicas voltadas para o Ensino Superior, são necessárias ações compartilhadas capazes de orientar e qualificar os educadores na formação de sujeitos, valorizando a diversidade e fazendo valer o sentido da inclusão enquanto processo de reconhecimento e respeito das diferentes identidades, aproveitando-as para beneficiar a todos. Para garantir a permanência e sucesso do aluno com NEE no Ensino Superior, é importante a adoção de políticas institucionais de acompanhamento que permitam identificar este aluno, compreender suas necessidades educativas e preparar professores e servidores para que possam atendê-las (MAZZONI; TORRES; ANDRADE, 2001). Consideramos também que "a importância dos recursos elaborados para alunos com deficiência visual está na possibilidade de participação, atuação e criação entre pessoas com e sem deficiência" (RAPOSO; MÓL, 2010, p. 309), levando a um "processo inclusivo no qual todos aprendem, independente [sic] de suas características individuais" (RAPOSO; MÓL, 2010, p. 309).

Foi neste contexto de Ensino Superior inclusivo, que realizamos essa pesquisa qualitativa, buscando compreender as dimensões do pensamento dos docentes de um curso superior de licenciatura em Química, frente ao processo de inclusão de uma discente cega.

\section{Inserção de alunos com deficiência visual em uma universidade pública}

A discente ingressante no curso de licenciatura em Química da universidade federal em foco é a sétima acadêmica cega atendida pela instituição e a primeira a pleitear formação na área de ciências exatas. As experiências anteriores desta instituição aconteceram nos cursos de jornalismo, pedagogia e letras (espanhol). A presença de discentes com baixa visão não foi registrada, talvez porque estes, por não se sentirem apoiados adequadamente, costumam buscar formas de superar sozinhos as barreiras que encontram.

Entende-se que a universidade não pode deixar de atender às especificidades desse grupo de pessoas, possibilitando-lhes o melhor acesso aos serviços nela existentes. Mesmo que, nos últimos anos, tenham sido registradas matrículas de alunos com NEE em diversos cursos, sobretudo com deficiência física e visual, as condições de infraestrutura que a institui- 
Regiani, A. M.; Mól, G. S.

ção apresenta para o atendimento dessas pessoas ainda são mínimas. Por outro lado, há uma grande expectativa e uma constante procura da comunidade ao atendimento a esses alunos, que geralmente têm receio de enfrentar o vestibular, devido às difíceis condições de permanência na instituição.

Em 2008, foi criado, em âmbito institucional, o Núcleo de Apoio à Inclusão (NAI). Este constitui uma das grandes possibilidades de realização de importantes objetivos socioeducacionais, por se propor a suprir as necessidades de adaptações curriculares e de outras ações afins, com vistas a atender aos princípios e objetivos da política nacional de inclusão.

\section{A inserção de discente com deficiência visual no curso de licenciatura em Química}

A informação, à coordenação do curso de licenciatura em Química da universidade federal em foco, sobre o ingresso de uma aluna deficiente visual aconteceu pouco depois do resultado do vestibular de ingresso em 2008, mas por meio informal. Em um encontro casual da coordenadora do curso com o então pró-reitor de Extensão e Cultura, este comentou sobre uma reportagem local televisionada cuja pauta era o ingresso de uma discente cega, aprovada na primeira colocação do curso. Também havia ingressado outro discente com visão reduzida na terceira colocação em outro curso. Quando a coordenação do curso informou, aos docentes da área de Química, sobre estes desafios, as reações mais comuns foram questionamentos do tipo: "Por que um cego quer fazer Química?”; “Como serão as aulas experimentais?”. Estes pensamentos, em nada positivos, refletem o paradigma da representação funcional já descrito por Rodrigues (2004). Para a maioria das pessoas, "ser químico" pressupõe um cientista hábil no trabalho em laboratório, circundado de líquidos coloridos e representações atômicas e moleculares tridimensionais. Como reportado por Camargo et al. (2007), estas questões do quadro docente refletem um conhecimento equivocado sobre as potencialidades e limitações de pessoas com deficiência visual. Este conceito segregacionista pode influenciar, de forma negativa, a receptividade, por parte do docente, e o sucesso do aluno, por considerar a visão como prérequisito para a compreensão de conceitos e teorias da Química. Além disso, esses professores consideram que alunos com deficiência visual não podem participar de atividades em um dos principais ambientes educacionais de um curso de Química: o laboratório. Essa "incapacidade", decorrência da impossibilidade de ver, limitaria a ação do aluno frente aos materiais e substâncias do laboratório (CAMARGO et al., 2007). Isto condicionaria alunos com deficiência visual a frequentarem cursos distintos dos cursos relacionados às ciências exatas.

Para este trabalho, contamos, basicamente, com duas fontes de informações: a entrevista feita com a aluna cega, e os dados obtidos por meio de questionário aplicado aos professores desta aluna.

A estudante cega foi entrevistada pela coordenação do curso com o objetivo de conhecer sua história e trajetória acadêmica. Neste caso, fizemos uso de uma entrevista semiestruturada, na qual os temas foram "particularizados e as questões (abertas) preparadas antecipadamente", mas com liberdade de alterações durante se percurso (LAVILLE; DIONE, 1999, 
p. 188). A discente, à época com 29 anos, contou que nasceu cega e que, até a sexta série, estudou em escola regular, quando desistiu de estudar. Este desestímulo aconteceu em virtude da falta de formação dos docentes do Ensino Fundamental, os quais pouco se mostravam interessados em incluí-la efetivamente. A maioria dos professores trabalhava como se ela não estivesse presente em sala de aula. Os argumentos comuns entre os docentes de Ensino Básico são: a falta de tempo, a formação insuficiente, a falta de apoio da escola e a falta de subsídios necessários para o preparo de atividades diferenciadas. O interesse da discente pelos estudos foi renovado após dez anos de reclusão, quando sua irmã ingressou no curso superior de Letras. Esse fato a estimulou a retomar as atividades escolares no programa de Ensino de Jovens e Adultos, com aulas de reforço no Centro de Apoio e Ensino ao Deficiente Visual (CEADV) de sua cidade. O entusiasmo de sua professora do CEADV em adaptar materiais de ensino de Química contagiou-a de tal forma que a fez inscrever-se no curso de licenciatura em Química. Quando arguida sobre as expectativas profissionais para a área escolhida, ela respondeu querer ser professora de Química, com preferência para atendimento a alunos cegos. A discente domina a grafia Braille, no entanto desconhecia a grafia química braille para uso no Brasil (BRASIL, 2002).

Desde o ingresso dessa aluna na universidade, a coordenação do curso de Química, preocupada com sua permanência, buscou apoio e informações em instituições especializadas, como o NAI, o CEADV e o grupo de pesquisa em Ensino de Química a Alunos com Deficiência Visual, da Universidade de Brasília. A primeira providência foi a realização de uma palestra, com um especialista da área, sobre ensino de Química para deficientes visuais. O evento alcançou o seu objetivo ao despertar docentes e discentes para o desafio proposto. Depois, foi oferecido um curso de grafia Braille, atentando-se para a existência do livro "Grafia braille em química para uso no Brasil” (BRASIL, 2002). Muitos discentes participaram, mas, infelizmente, poucos docentes se interessaram.

A segunda forma de coleta de dados tinha como objetivo conhecer melhor a formação dos docentes do curso de Química, suas necessidades e ideias relacionadas ao ensino inclusivo. Para isso, foi proposto que respondessem a um questionário. De acordo com Laville e Dione (1999, p. 183), o questionário é um "instrumento privilegiado de sondagem" que "permite alcançar rápida e simultaneamente um grande número de pessoas". O questionário aplicado buscava informações sobre: o perfil dos professores (idade e gênero), formação acadêmica (graduação, licenciatura ou bacharelado, pós-graduação) e conhecimentos sobre inclusão de alunos com NEE. Buscava também, por meio de questões abertas, informações sobre: a percepção do docente sobre a presença da aluna cega no curso de Química, as funções do NAI e da coordenação, condições necessária para a acessibilidade e permanência desta aluna na instituição, e seus sentimentos sobre a presença dessa aluna em sala de aula. O questionário foi entregue a 22 docentes que ministravam disciplinas no curso de licenciatura em Química no primeiro semestre de 2009 , solicitando-se que o devolvessem respondido à coordenação do curso em um prazo de 15 dias: 17 professores responderam à demanda. Deste conjunto, dois eram da área de Matemática, um de Biologia, sete de Química, um de Física e seis da área de Educação. 
Regiani, A. M.; Mól, G. S.

\section{Pensamentos de docentes frente à inclusão de uma aluna cega no curso de licenciatura em Química}

Pela análise dos questionários, constatamos que a maioria do corpo docente do curso de licenciatura em Química, no primeiro semestre de 2009, é do gênero masculino (12 docentes) e com idade média de 39 anos, tendo o mais novo 29 anos e o mais velho 53. Dois professores possuem pós-graduação em nível de especialização, sendo um deles especialista em Educação Especial; dois têm mestrado incompleto; cinco são mestres, sendo que um está cursando doutorado; cinco são doutores, sendo que dois têm pós-doutorado. Com relação à atuação profissional, seis têm experiência em ensino nos níveis fundamental, médio e superior, dois nos níveis fundamental e superior, três nos níveis médio e superior, e cinco têm experiência de docência apenas em nível superior. $O$ tempo de experiência no Ensino Superior é bastante variado: dez docentes têm menos de cinco anos; dois docentes têm entre seis e dez anos de experiência; dois tem experiência entre 11 e vinte anos; e dois afirmaram ter 29 anos de experiência docente em nível superior.

Com relação à formação em graduação, sete docentes afirmaram serem licenciados e seis são bacharéis. Dois têm dupla formação (licenciatura e bacharelado). Nesta análise dos dados, observou-se que o conjunto de professores do curso de licenciatura em Química, com uma exceção, não teve nenhuma formação para a educação inclusiva, ou vivências pessoais, na Educação Básica e formação profissional. A formação de professores, no magistério superior, para áreas que não são pedagógicas, geralmente, não conta com disciplinas que preparem para o ensino em seus currículos (ROCHA; MIRANDA, 2009). Mesmo os licenciados, por haverem estudado em épocas anteriores à legislação no ensino a educandos com NEE do Ministério da Educação, também não tiveram, em sua formação inicial, discussões sobre o atendimento a esses alunos. Esta análise foi confirmada ao se observarem as respostas à pergunta que questionava se a formação em graduação havia proporcionado conhecimentos sobre educação inclusiva. Apenas duas professoras informaram terem participado de atividades em escolas especiais durante a formação. Uma delas atuou por 18 anos em atendimento educacional a alunos surdos, hoje trabalha no NAI e é professora da disciplina Fundamentos de Educação Especial, ministrada nos cursos de licenciatura da Universidade.

Os docentes, aqui representados pela letra $\mathrm{P}$ seguida de um número, também foram questionados sobre o conhecimento da presença da discente cega no curso e a da existência e atuação do Núcleo de Apoio à Inclusão, NAI. Um terço dos docentes que responderam ao questionário declarou-se professor desta aluna; cinco ainda desconheciam a sua presença no curso; três souberam através da coordenação, e cinco souberam por outros colegas de profissão. Apenas três docentes informaram não conhecer o NAI. Sete dos entrevistados que conhecem a existência deste setor não sabem como ele funciona e nem qual é o seu papel institucional.

Sobre as condições de acessibilidade de discentes com NEE, um professor afirmou que não as conhece; dois acreditam que sejam satisfatórias; dois informaram que há pouca divulgação das condições de acessibilidade, e oito docentes as acham precárias ou inadequadas. Um docente (P10) declarou que a questão deve ser melhor analisada, levando-se em conta a especificidade do curso. Ele não é favorável a "colocar um aluno em um espaço que não the oferece as condições necessárias". Esta declaração revela a concepção de um modelo educacional segregativo (CAMARGO et al., 2007) e representa um grupo de pessoas que acredita que, 
primeiro, a escola tem de se preparar, para, depois, receber esses alunos. Mazzoni, Torres e Andrade (2001) reportam que a maior barreira a ser superada no Ensino Superior é a ignorância dos docentes em saber se relacionarem com o aluno com NEE.

Outro docente ainda declarou

“[...] a acessibilidade ou ingresso à universidade se dá de forma satisfatória, com vestibular assistido; a permanência ainda é fator crítico em alguns casos, por falta de estímulo ao aluno com NEE (adequação de material didático e convívio social)". (P6)

Esta declaração revela a concepção do contexto universitário concordante com o modelo inclusivo, no qual as instituições educacionais se adaptam para poderem incluir pessoas com NEE em seus ambientes (CAMARGO et al., 2007). Dessa forma,

[...] a permanência na graduação é mais uma barreira a ser enfrentada pela pessoa com deficiência, uma vez que demanda por parte do IES não só a vontade, mas sobretudo a sensibilidade e a preocupação em adaptar o acesso ao currículo pelos alunos com deficiência, bem como preparar os professores e funcionários para o atendimento desse aluno em sala de aula e demais setores e serviços da instituição. (ANDRADE; PACHECO; FARIAS, 2006, p. 4)

O docente vinculado ao NAI informou que a implantação de ações afirmativas abertas às diferenças já havia sido iniciada na instituição, porém ainda requeria uma instrumentalização e solidificação por parte da comunidade docente da IES em questão.

Quando indagados sobre o sentimento próprio frente à presença da aluna cega, declaram-se temerosos e diante de um desafio. Alguns pontuam a necessidade de revisão da postura didática usual e o desenvolvimento de metodologia diferente para atender às diferenças. As declarações, transcritas a seguir, revelam um modelo educacional inclusivo, valorizando o envolvimento do docente na ação pedagógica.

"O docente precisa entrar no universo desse aluno para enxergar e definir como abordará suas aulas”. (P9)

"Há de se rever a postura didática usual, pois a mesma não teria efeito sobre o caso vivenciado (aluna cega)". (P6)

"Senti a importância de se desenvolver de forma especial uma metodologia de ensino para atender às diferenças individuais de cada aluno, através da diversificação dos serviços educacionais". (P7)

"No começo fiquei um pouco preocupado, mas tentei me informar melhor para preparar aulas em que ela pudesse participar efetivamente. Não tive problemas, pelo contrário, os resultados foram excelentes". (P9) 
Regiani, A. M.; Mól, G. S.

Apesar das declarações com perspectivas inclusivas, um dos docentes fez a seguinte afirmação:

“[...] me senti desrespeitado por não estar preparado, pela coordenação nunca ter colocado um plano de ação para melhor atendê-la e pela própria aluna não estar apta a ingressar num curso de Química”. (P17)

A declaração do docente P17 mostra que o mesmo se exime da responsabilidade do processo inclusivo, ou seja, o problema da inclusão não é seu, mas sim da instituição e do aluno. Podemos classificar esta declaração como típica do modelo educacional segregativo de causa estrutural, pois se refere às condições do ambiente para o estabelecimento ou não de atitudes de inclusão, e sem possibilidade de adequação, porque a responsabilidade da inclusão é da coordenação do curso e da aluna. A declaração também remete a algumas reflexões. O sentimento de desrespeito assemelha-se ao medo declarado por outros professores e decorre do conhecimento equivocado das potencialidades e limitações de uma pessoa cega. Cabe lembrar que a aluna foi a primeira colocada no vestibular para o curso de Química. Este sentimento é agravado pela sensação de falta de preparo. No processo de contratação de docentes em universidades públicas é de praxe valorizar a produção científica do candidato, concentrando a sua seleção com vistas a sua formação em pós-graduação e publicações, na expectativa de que este trabalho continue na vida acadêmica em uma instituição onde o ensino é o foco principal. Esta prática acontece em virtude da necessidade de atendimento, dos cursos de graduação e pós, a uma série de exigências do Ministério de Educação e das agências de fomento, notadamente a Coordenação de Aperfeiçoamento de Pessoal de Nível Superior (Capes) e o Conselho Nacional de Desenvolvimento Científico e Tecnológico (CNPq), como critério de avaliação dos cursos. Assim, formam-se quadros docentes extremamente especializados e qualificados tecnicamente, aptos a realizar a prática de pesquisa com "excelência". Nesse quadro, a docência fica relegada a segundo plano. Há o senso comum de que se aprende a ministrar aulas com o tempo, bastando o domínio do conteúdo. É de grande importância a discussão sobre a introdução, nos currículos dos programas de mestrado e doutorado brasileiros, de temáticas da área de educação, uma vez que a maioria dos pós-graduados no Brasil encontra acolhimento nas universidades. A formação pedagógica dos professores universitários deve ser pensada de modo a contribuir para que estes desenvolvam uma prática mais reflexiva e comprometida ética e politicamente com as exigências do contexto atual, em especial da educação inclusiva (VITALIANO, 2007). Vale lembrar que a instituição deve dar suporte aos professores desses alunos, o que tem sido feito desde o ingresso da citada aluna, por meio de palestra, cursos e outras formas de apoio fornecidas pelo NAI.

Os docentes também foram questionados sobre as medidas que tomaram para favorecer a inclusão da aluna cega no meio acadêmico. $\mathrm{Na}$ análise das resposta, foi possível observar que o processo de inclusão acontece segundo as características da disciplina. Um dos docentes declarou que

"A disciplina lecionada dava possibilidade de discussões em grupos e os textos eram preparados com antecedência pelo pessoal do NAI. 
Assim, a aluna conseguiu se inserir nas discussões com resultados satisfatórios". (P9)

Outros promoveram a integração dos demais alunos no processo inclusivo. Na disciplina Fundamentos de Química 13, os discentes foram convidados a construir e produzir modelos em maquetes ou em alto-relevo com a participação da discente cega que opinava sobre os materiais construídos. Na disciplina Educação Ambiental e Saúde ${ }^{4}$ o docente propôs, aos alunos videntes, a construção de projeto sobre reconhecimento de materiais através do tato, olfato e audição e suas reciclagens. As propostas desenvolvidas pelos alunos foram apresentadas pelos mesmos, sob supervisão do docente, no CEADV. Alguns docentes optaram por solicitar a transcrição do material preparado para o Braille através do NAI. Entretanto, alegaram que este é um processo lento devido à burocracia institucional na liberação de recursos. Um docente $(\mathrm{P} 7)$ declarou que ainda não havia lecionado para a aluna e sugeriu a "realização de um diagnóstico educacional por uma equipe interdisciplinar para recomendar, de acordo com cada caso, a educação especial". Mais uma vez, aparece a preocupação docente com a inclusão e com a busca de respaldo institucional para que este processo seja realizado de forma mais efetiva.

Quando questionados sobre as principais dificuldades para o exercício do magistério em turma com a presença de discentes com NEE, os docentes apontam, sobretudo, a falta de conhecimento sobre a linguagem do aluno e sua deficiência. Ainda são apontadas as seguintes questões: falta de infraestrutura e de material didático adequado; a preocupação com as aulas de laboratório, e a necessidade de tempo e de orientação para o preparo do material didático. Essas preocupações são retomadas nas declarações relacionadas ao pensamento sobre o processo de inclusão, o qual, segundo os docentes, é dever do Estado, baseado no direito à educação. Eles também denotam a preocupação com a falta de capacitação profissional e institucional, o que torna o ensino inclusivo complicado. Em decorrência desta ausência de recursos, alguns professores indicam a retomada da educação diferenciada em espaços especializados. Mesmo diante da complexidade do ensino inclusivo, reconhecem a sua importância para a conscientização e respeito sobre a diversidade que constitui a sociedade.

\section{Considerações finais}

A presença de uma discente com NEE no Ensino Superior leva-nos à reflexão de que a educação inclusiva, também neste nível, requer a reconstrução dos sistemas de ensino, com necessidade para a superação das barreiras pedagógicas. Essas barreiras não se limitam à infraestrutura física necessária. A maioria dos docentes apontou a carência de materiais didáticos e o próprio despreparo para a interação com as necessidades específicas como causa do insucesso na formação da discente cega.

\footnotetext{
${ }^{3}$ Informação pessoal obtida em conversa dos autores com os docentes das disciplinas à época.

${ }^{4}$ Informação pessoal obtida em conversa dos autores com os docentes das disciplinas à época.
} 
Regiani, A. M.; Mól, G. S.

Esta falta de preparo e informação dos docentes sobre métodos de ensino, materiais didáticos adaptados e a falta de comunicação entre professores e esses alunos gera uma lacuna que dificulta o acesso e a permanência do educando com NEE no Ensino Superior (ANDRADE; PACHECO; FARIAS, 2006; ROCHA; MIRANDA, 2009). Para que aconteça a compreensão das necessidades educativas de cada indivíduo, é importante o esforço institucional de formação e preparo de docentes e servidores. Para além das políticas públicas e determinações do Ministério da Educação, esta é uma tarefa conjunta da comunidade acadêmica, envolvendo todos os seus atores (professores, alunos, servidores e corpo diretivo).

Essa situação vivenciada pelos envolvidos no curso de Química tem mostrado que, apesar das dificuldades, a aluna cega tem capacidade para acompanhar o curso escolhido, fazendo com que muitos mudem sua posição sobre a possibilidade de uma pessoa cega poder se tornar um Químico. Como dizemos, ela será uma Química diferente, como todos somos. Cada um faz suas opções durante a vida acadêmica e profissional em função de habilidades, opções econômicas, sociais, ambientais etc. Por isso, alguns optam por serem teóricos e, depois do curso, nunca mais realizam qualquer procedimento em laboratório, como uma simples titulação. Outros ficam no laboratório e esquecem as funções de onda.

É importante ressaltar, também, a importância da aluna no curso. Sua presença e convivência com os colegas contribuem para a formação de professores mais capacitados a lidarem com as diferenças, por vivenciarem um processo de inclusão e, dessa forma, acreditarem cada vez mais que isso é possível e viável. Por isso, defendemos que a inclusão é boa não só para os "incluídos", mas, sim, para toda a comunidade que participa e vivencia o processo.

\section{Agradecimentos}

Às professoras Joseane Lima Martins e Maria do Perpétuo Socorro Morais, do Núcleo de Apoio à Inclusão da Universidade Federal do Acre.

\section{Referências}

ANDRADE, M. S. A. de; PACHECO, M. L.; FARIAS, S. S. P. Pessoas com deficiência rumo ao processo de inclusão na educação superior. Conquer, Barreiras, v. 1, p. 1-5, 2006. Disponível em: <http://issuu.com/uc-para-todos/docs/

13._pessoas_com_defici_ncia_rumo_ao_processo_de_in >. Acesso em: 17 set. 2010.

BRASIL. Lei no 9.394, de 20 de dezembro de 1996. Estabelece as diretrizes e bases da educação nacional. Diário Oficial da União, Brasília, DF, 23 dez. 1996. Disponível em: <http://www.planalto.gov.br/ccivil_03/leis/19394.htm>. Acesso em: 16 fev. 2009.

. Ministério da Educação. Secretaria de Educação Especial. Grafia química braille para uso no Brasil: versão preliminar. Brasília, 2002. 
Inclusão de uma aluna cega ...

CAMARGO, E. P. de et al. Alunos com deficiência visual em um curso de química: fatores atitudinais como dificuldades educacionais. In: ENCONTRO NACIONAL DE PESQUISA EM EDUCAÇÃO EM CIÊNCIAS, 6., 2007, Florianópolis. Anais... São Paulo: Abrapec, 2007. p. 1-15. Disponível em: <http://www.nutes.ufrj.br/abrapec/vienpec/ autores0.html>. Acesso em: 07 maio 2010.

CASTANHO, D. M.; FREITAS, S. N. Inclusão e prática docente no ensino superior. Revista Educação Especial, Santa Maria, n. 27, p. 85-92, 2006. Disponível em: < http:// cascavel.ufsm.br/revistas/ojs-2.2.2/index.php/educacaoespecial/article/view/4350/2557>. Acesso em: 04 abr. 2009.

FERREIRA, S. L. Ingresso, permanência e competência: uma realidade possível para universitários com necessidades educacionais especiais. Revista Brasileira de Educação Especial, Marília, v. 13, n. 1, p. 43-60, 2007.

LAVILLE, C.; DIONNE, J. A construção do saber: manual de metodologia da pesquisa em ciências humanas. Belo Horizonte: Ed. UFMG, 1999.

MAZZONI, A. A.; TORRES, E. F.; ANDRADE, J. M. B. Admissão e permanência de estudantes com necessidades educativas especiais no ensino superior. Acta Scientiarum, Maringá, v. 23, n. 1, p. 121-126, 2001.

MOREIRA, L. C. In(ex)clusão na universidade: o aluno com necessidades educacionais especiais em questão. Revista Educação Especial, Santa Maria, n. 25, p. 37-47, 2005. Disponível em: < http://cascavel.ufsm.br/revistas/ojs-2.2.2/index.php/educacaoespecial/ article/view/4902>. Acesso em: 04 maio 2009.

PACHECO, R. V.; COSTAS, F. A. T. O processo de inclusão de acadêmicos com necessidades educacionais especiais na Universidade Federal de Santa Maria. Revista Educação Especial, Santa Maria, n. 27, p. 151-170, 2006. Disponível em: < http:// cascavel.ufsm.br/revistas/ojs-2.2.2/index.php/educacaoespecial/article/view/4360>. Acesso em: 04 maio 2009.

RAPOSO, P. N.; MÓL, G. S. A diversidade para aprender conceitos científicos: a ressignificação do ensino de ciências a partir do trabalho pedagógico com alunos cegos. In: SANTOS, W. L. P.; MALDANER, O. A. (Org.). Ensino de Química em foco. Ijuí: Edit. Unijuí, 2010. p. 287-312.

ROCHA, T. B.; MIRANDA, T. G. Acesso e permanência do aluno com deficiência na instituição de ensino superior. Revista Educação Especial, Santa Maria, v. 22, n. 34, p.197-212, 2009. Disponível em: <http://cascavel.ufsm.br/revistas/ojs-2.2.2/index.php/ educacaoespecial/article/view/273/132>. Acesso em: 17 set. 2010.

RODRIGUES, D. A inclusão na universidade: limites e possibilidades da construção de uma universidade inclusiva. Revista Educação Especial, Santa Maria, n. 23, p. 9-15, 2004. Disponível em: <http://cascavel.ufsm.br/revistas/ojs-2.2.2/index.php/educacaoespecial/ article/view/4951>. Acesso em: 04 maio 2009. 
Regiani, A. M.; Mól, G. S.

THOMA, A. S. A inclusão no ensino superior: ninguém foi preparado para trabalhar com esses alunos... isso exige certamente uma política especial. In: REUNIÃO ANUAL DA ANPED, 29., 2006, Caxambu. Anais... Caxambu: Anped, 2006. p. 1-18. Disponível em:<http://www.anped.org.br/reunioes/29ra/29portal.htm >. Acesso em: 17 set. 2010. VITALIANO, C. R. Análise da necessidade de preparação pedagógica de professores de cursos de licenciatura para inclusão de alunos com necessidades educacionais especiais. Revista Brasileira de Educação Especial, Marília, v. 13, n. 3, p. 399-414, 2007.

Artigo recebido em 06/02/12. Aceito em 08/07/12. 